\title{
Thorite, a new mineral, and thorina, a new earth
}

\section{Berzelius}

To cite this article: M. Berzelius (1829) Thorite, a new mineral, and thorina, a new earth, Philosophical Magazine Series 2, 6:35, 392-393, DOI: 10.1080/14786442908675174

To link to this article: http://dx.doi.org/10.1080/14786442908675174

曲 Published online: 14 Jul 2009.

Submit your article to this journal

Џ Article views: 6

Q View related articles $\sqsubset$ 
tices are conducted with the greatest skill, my sons can testify that the mere name of an English miner every where called forth the kindest welcome, and every where opened the door to all kinds of information which they were in search of; I therefore cordially cherish the feeling that we ought not to be outdone in such genetous sentiments.

I would fain, gentlemen, now communicate to you how I am impressed by the honours you have conferred on me this day; but in this I should fail if $I$ ventured to enlarge upon it, and I must attempt but little, inadequate as any thing I could say would be to give a just picture of my feelings on this-occasion. Arduous and almost overpowering as tnany of my duties have been, 1 have been cheered on by the kindness of friends, or by those who have reaped advantage from successful efforts; - how much more must I value this unlooked-for and spontaneous expression of approbation from those whose regard is so disinterested, whose favour I have had so few means of cultivating ! Gentlemen, the impression you have made on my mind is too deep to vent itself in complimentary words; it will remain $a$ theme of grateful recollection and a stimulus to exertion, and it will associate itself with all thebest wishes for you and yours that you can desire or that I can offer.

\section{THORITE, A NEW MINERAL, AND THORINA, A NEW EARTH.- BY M. BERZELIUS.}

A new mineral substance, discovered near Brevig in Norway by M. Esmark, was sent to me for examination. It is compact and black, brittle and semi-hard; it has the vitreous fracture of gadolinite; when powdered it is of a dark brown colour; its sp. gr. is 4.8 . Under the flame of the blowpipe it loses water, and becomes yellow. This mineral is a new earth, which has so many properties belonging tc the substance formerly called thorina, that I thought at first the mineral aetually contained it. This was not confirmed by experiment, but I have nevertheless retained the name of thorima. This mineral is constituted of

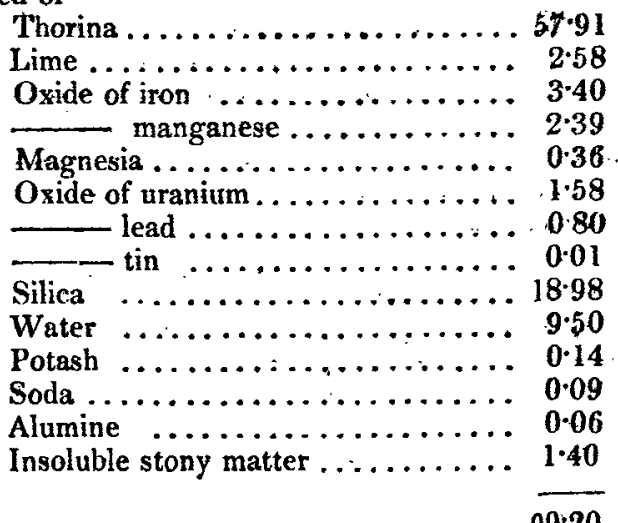


Thorina possesses the following properties : it is colourless and infusible, and when it has been heated to strong redness, it is insoluble in all acids except the sulphuric; it is not rendered soluble in other acids by calcination with an alkali. It is insoluble in caustic potash, but soluble when taken up by the carbonate, from which it is partially precipitable by heat, but redissolves in the cold. Its salts hare a purely styptic taste. Sulphate of thorina, when the solution is strong, becomes a thick mass by boiling, but it is soluble in cold water; this property characterizes the new, earth very particularly. Sulphate of potash, when the solution is saturated, produces a precipitate in it; this character belongs also to the salts of cerium; the precipitate is a double salt, soluble in pure water. Ferrocyanate of potash precipitates it as it does yttria.

Potassium does not reduce thorina, but the chloride of thorinium readily; this chloride may be obtained in the same manner as that of aluminum. The reduction is accompanied with a feeble detonation. The product is a powdery, grey metallic mass, which dissolves very rapidly in muriatic acid, but very slowly in nitric and sulphuric acids. Neither water nor the alkalies act upon this metal. By rubbing it acquires a lustre; it burns in oxygen gas with a brilliancy which may be compared to that of phosphorus. The colourless earth is regenerated, and without undergoing fusion. Thorina contains $11.8 \mathrm{per}$ cent of oxygen.-Hensman's Repertoire, June 1829.

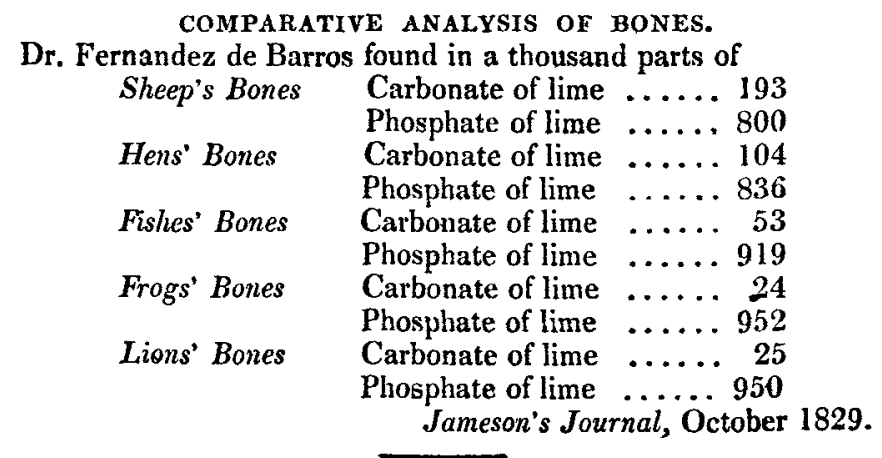

ACTION OF ETHER ON SULPHATE OF INDIGO.

M. Cassola states that when sulphuric æather is added to sulphate of indigo, in about half an hour, at a temperature of about $30^{\circ}$ Reaumur, the colour of the indigo totally disappears, and no substance whatever is capable of restoring it.

The colourless mixture being subjected to distillation, yielded a liquor which reddened litmus strongly, and gave no precipitate with barytic salts ; but with a solution of nitrate of silver a precipitate was obtained, soluble in ammonia.-Hensman's Repertoire, April 1829. 